\title{
Sensitivity analysis of the artificial neural networks in a system for durability prediction of forging tools to forgings made of C45 steel
}

\author{
Barbara Mrzygłód ${ }^{1}$ (D) $\cdot$ Marek Hawryluk $^{2} \cdot$ Marta Janik $^{3} \cdot$ Izabela Olejarczyk-Wożeńska $^{1}$
}

Received: 2 December 2019 / Revised: 9 June 2020 / Accepted: 15 June 2020 / Published online: 9 June 2020 / Published online: 15 July 2020

(C) Springer-Verlag London Ltd., part of Springer Nature 2020

\begin{abstract}
The article presents the results of a sensitivity analysis of artificial neural networks developed for a system which predicts the durability of forging tools used in the selected hot die forging process. The developed system makes it possible to calculate the geometric loss of the examined tool for the given values of its operating parameters (number of forgings, tool temperature at selected points, type of the applied protective layer, pressure and path of friction) and estimates the intensity of the occurrence of typical mechanisms of tool destruction, i.e. thermo-mechanical fatigue, mechanical wear, abrasive wear and plastic deformation. Nine neural networks operate in the developed system. Five of them determine the geometric loss of the material used for tools operating with protective layers, including a nitrided layer, a pad welded layer and three hybrid layers, i.e. $\mathrm{AlCrTiSiN}, \mathrm{Cr} / \mathrm{CrN}$ and $\mathrm{Cr} / \mathrm{AlCrTiN}$. Four networks make calculations determining the intensity of the occurrence of typical destructive mechanisms. The developed sensitivity analysis allows for each neural network to show which input parameters are most important and have the greatest impact on the explained variables. This is determined based on the network error analysis in the case of elimination of individual variables from the input data. The greater the network error calculated after rejecting an input variable relative to the error obtained for the network with all the input variables, the more sensitive the network to the lack of this variable. The best compliance was obtained for the first developed set of networks regarding the geometric loss of material, while the lowest compliance was obtained for the second developed set of networks regarding the applied protective layers, and in particular for plastic deformation and mechanical fatigue, probably due to the smallest size of these sets in the knowledge base. The obtained results of this analysis are important for the system operation, i.e. supporting the technologist's decision in the selection of such process parameter values that will increase the die's lifetime.
\end{abstract}

Keywords Durability of forging tools $\cdot$ Loss of material, artificial neural network $\cdot$ Sensitivity analysis

Barbara Mrzygłód

mrzyglod@agh.edu.pl

Marek Hawryluk

marek.hawryluk@pwr.edu.pl

Marta Janik

marta.janik@pl.mahle.com

Izabela Olejarczyk-Wożeńska

iolejarc@agh.edu.pl

1 AGH University of Science and Technology, Faculty of Metals Engineering and Industrial Computer Science, Al. Adama Mickiewicza 30, 30-059 Krakow, Poland

2 Wroclaw University of Technology, Faculty of Mechanical Engineering, 5 Lukasiewicza Street, 50-370 Wrocław, Poland

3 Mahle Poland, Mahle 6, 63-700 Krotoszyn, Poland

\section{Introduction}

In forging companies producing hot die forgings, the durability of forging tools is an important and at the same time complex scientific and economic issue. This is due to the significant contribution of the cost of forging tools to the total production costs calculated per one forging item. Therefore, durability is often expressed in the number of geometrically and qualitatively correct forgings obtained from a single forging tool. It is currently estimated that the cost of one forging consumes on average $30 \%$ of the tool cost, depending on the durability value (the number of forgings produced), but this value can go up to as much as even $60 \%$ in some extreme cases of intricate steel forgings or forgings made from austenitic steel. It means that the higher the durability, the lower the 
price of the forgings [1]. The wear process of forging instrumentation is also complicated and difficult to analyse, especially that it is affected by many, often simultaneously occurring, phenomena and destructive mechanisms, such as thermo-mechanical fatigue, abrasive wear, plastic deformation, mechanical fatigue and oxidation [2-4]. The contribution of individual mechanisms varies depending on the type of the die (its shape and size, thermal and thermo-chemical treatment) as well as the working conditions (type of forging machine, lubrication, temperature of tool and forged material, etc.). Moreover, the contribution of individual mechanisms to the total wear of a given tool may also change during operation. Usually, a grid of fatigue cracks appears at the beginning, followed by abrasive wear, tempering of the material and its local plastic deformation [5]. The phenomena of thermal fatigue and combined thermal and mechanical fatigue also appear [6-8], but abrasive wear is not necessarily dominant in this case. Hence, thoroughly analysing the wear of forging tools and predicting their life is a very important issue and a huge challenge for technologists, tool designers, process engineers and forging companies, as well as many research centres $[9,10]$. Numerous studies described in the technical literature are devoted, on the one hand, to research works which make it possible to increase the tool life by various techniques of surface engineering [11-16] and, on the other, to improvements of the technical and technological process parameters [17], optimization of the tool shape [18], conversion of the tool material to a material more resistant to the effect of destructive mechanisms [19, 20], or implementation of proper heat treatment [21].

One could also not overestimate the possibility of using modern information technologies (IT) for the support of the processing operations. A development of the IT field can be noticed both in the aspect of the increased possibilities of measurement and storage of a very big number of technological parameters and with respect to providing many new methods and algorithms for the processing of the latter [22]. This makes it possible to construct computer systems which enable a partial replacement of the costly and time-consuming material experiments performed by way of computer simulations. In the literature, one can find many publications describing computer systems developed to support the forging processes [22-34]. The main goal of all these works is to investigate the financial and ecological aspects of materials production, combined with the scientific and cognitive goals aiming at a continuous improvement of the forging process technology and development of new solutions and technologies [1].In [28], an artificial neural network was developed. It was used to determine the relationship between the mechanical properties and deformation as well as the technological parameters of a titanium alloy. On the other hand, in work [29], based on the measurement data, an optimal model of parameters for the hot forming process of the Ti-6Al-4V alloy was developed, owing to the use of a combination of artificial neural networks and genetic algorithms. In turn, fuzzy logic was used to write the rules for the knowledge base of a special decision system [30], as well as to develop an expert system to forecast the results of the finite element method analysis (FEM), while solving the problem of rubber cylinder compression [31]. In paper [32], an expert system was developed to forecast the loads and axial stresses during forging, while paper [33] presents the use of the finite element method and an intelligent system for the prediction of the values of pressure during a radial forging process.

The investigations carried out by the authors, both in the area of analysing the forging tool durability, including manyyear studies of industrial forging processes, and the long-term research related to the analysis of the formal methods of creating computer systems supporting these processes, have led to the development of an expert system which predicts the durability of forging tools and makes it possible to calculate the value of the geometrical loss of the analysed tool for the predetermined parameter values of its work. The system can also estimate the intensity of the occurrence of typical destruction mechanisms. During the work on this system, many formal methods of computer knowledge representation were considered. The basis for its creation was the results of a many-year industrial research collected in the elaborated database, and so the analysis was performed mainly with the use of formal methods, which, in their nature, make it possible to model a phenomenon based on the collected data. As the results of materials experiments are incomplete and burdened with error, the investigations were carried out with the use of fuzzy logic [34], which works perfectly with uncertain and incomplete knowledge as well as neuro-fuzzy algorithms ANFIS [35]. The best matching and the smallest error were, however, achieved with the use of artificial neural networks. The works [24-26] present a methodology of system creation, the parameters and architectures of the developed networks as well as an analysis of the results obtained by means of the elaborated system.

This study concerns a sensitivity analysis of artificial neural networks developed for a system predicting the durability of forging tools used in hot die forging processes. There are nine neural networks in the system subjected to the analysis.

A sensitivity analysis of the developed neural networks gives the opportunity to assess the input variables in terms of the importance of their impact on the output variable and indicate insignificant variables.

This work is a completion of the research performed by the authors. It makes it possible to confirm the importance of the variables applied in the neural networks as well as to sequence them starting from the most important ones to the ones of the least impact. Such information can turn out crucial for the users of the system (technologists), whose task is to optimize the working 
parameters of the process in such a way so as to maximize the forging tool durability.

\subsection{Characteristics of developed neural networks operating in the decision support system}

The developed system forecasting the durability of forging tools used in the selected hot die forging process is precisely this type of solution. A simplified schematic diagram of the structure of this system is shown in Fig. 1.

\subsection{Data set}

As part of the research works aimed at the system development, the following tasks were accomplished: operational tests carried out on the selected industrial hot die forging process after different numbers of cover-type forgings have been manufactured. Additionally, the selected tools (punches used in the second upper die forging operation) were covered with three different variants of hybrid layers (gas nitrided layer GN + PVD coating) were applied, i.e. GN/AlCrTiN, GN/ AlCrTiSiN and GN/CrN, to increase their durability. The tools with the hybrid layers were compared with standard tools subjected only to gas nitriding and regenerative surfacing. Material and simulation tests were carried out, which included macroscopic testing of the tool surface-a macroscopic surface analysis enabling a visual assessment of the degree of tool wear, dimensional analysis-3D scanning of the worn-out tools which were used to manufacture different numbers of forgings and an analysis of selected areas on the working surface of each tool applying the following research techniques:

- numerical modelling (FEM) using the following calculation packages: Marc Mentat, QForm, Forge,

- HV 0.1 microhardness measurements,

- optical microscopy,

- scanning electron microscopy (SEM).
The developed set of training data included a collection of about 900 knowledge records. Figure 2 presents a fragment of the developed set, while the details related to the knowledge acquisition are described in ref. [24, 25].

The input (explanatory) variables included the number of produced forgings, the pressures, the temperature on selected surfaces of the tool, the friction path and the type of protective layer deposited on the tool surface. The output (explained) variables included the geometric loss of the tool material and the percentage contribution of the four main destructive mechanisms.

\subsection{Artificial neural network models}

The second stage of the research work was related to the use of the developed database to design a model of the analysed process. The main aim was to determine the following parameters:

- the size of the tool's geometric loss (Z) in the normal direction (wear), in a specific area, with fixed values of the forging process parameters: $\mathrm{L}_{0}$ - number of forgings; $\mathrm{N}-$ pressure; $\mathrm{T}_{\mathrm{m}}-$ tool temperature; $\mathrm{d}_{\mathrm{t}}-$ path of friction; $\mathrm{R}$ - type of surface layer;

- contribution to die wear of the four basic wear mechanisms $(T): Z_{c m}$-thermal and mechanical fatigue; $Z_{\mathrm{s}}-$ abrasive wear; $\mathrm{O}_{\mathrm{pl}}$ - plastic deformation; $\mathrm{Z}_{\mathrm{m}}$-mechanical fatigue, for the examined PN + PVD hybrid layers, i.e. GN/CrN, GN/AlCrTiN, GN/AlCrTiSiN and tools after pad welding and sole nitriding.

In the case of the system described in this paper, the formal method of knowledge representation was based on artificial neural networks, which were developed with the use of a set of training data collected in industrial research. The best values showing the quality of the neural regression model were obtained by multilayer perceptrons (MLP). To solve the posed problems, a set of nine MLP neural network models was

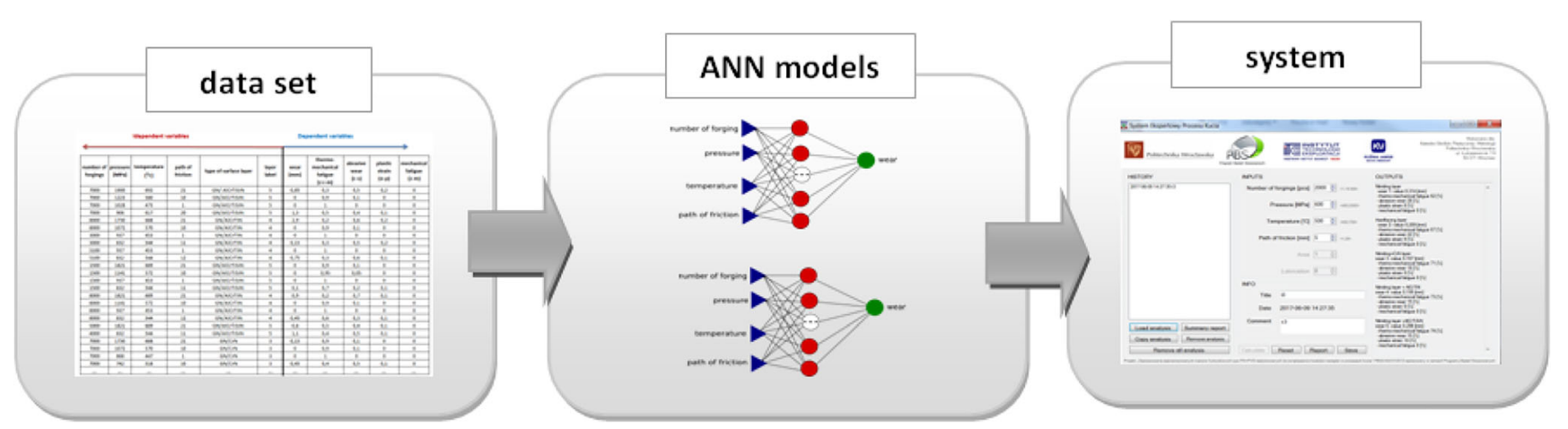

Fig. 1 A simplified diagram of the system structure 
Dependent variables

\begin{tabular}{|c|c|c|c|c|c|c|c|c|c|c|}
\hline $\begin{array}{c}\text { number of } \\
\text { forgings }\end{array}$ & $\begin{array}{c}\text { pressure } \\
{[\mathrm{MPa}]}\end{array}$ & $\begin{array}{c}\text { temperature } \\
{\left[{ }^{\circ} \mathrm{C}\right]}\end{array}$ & $\begin{array}{c}\text { path of } \\
\text { friction }\end{array}$ & type of surface layer & $\begin{array}{c}\text { layer } \\
\text { label }\end{array}$ & $\begin{array}{c}\text { material } \\
\text { loss } \\
{[\mathrm{mm}]}\end{array}$ & $\begin{array}{c}\text { thermo- } \\
\text { mechanical } \\
\text { fatigue } \\
\left(\mathrm{Z}_{c-\mathrm{m}}\right)\end{array}$ & $\begin{array}{c}\text { abrasive } \\
\text { wear } \\
\left(\mathrm{Z}_{2-\mathrm{s}}\right)\end{array}$ & $\begin{array}{c}\text { plastic } \\
\text { strain } \\
\left(\mathrm{Z}_{0-\mathrm{p}}\right)\end{array}$ & $\begin{array}{c}\text { mechanical } \\
\text { fatigue } \\
\left(\mathrm{Z}_{2-\mathrm{m}}\right)\end{array}$ \\
\hline 7000 & 1900 & 692 & 21 & $\mathrm{GN} /$ AlCrTiSiN & 5 & 0,85 & 0,3 & 0,5 & 0,2 & 0 \\
\hline 7000 & 1223 & 580 & 10 & GN/AlCrTiSiN & 5 & 0 & 0,9 & 0,1 & 0 & 0 \\
\hline 7000 & 1028 & 473 & 1 & GN/AlCrTiSiN & 5 & 0 & 1 & 0 & 0 & 0 \\
\hline 7000 & 906 & 617 & 20 & GN/AlCrTiSiN & 5 & 1,3 & 0,5 & 0,4 & 0,1 & 0 \\
\hline
\end{tabular}

Fig. 2 Fragment of the developed data set

developed. The details related to the network design are described in ref. [24].

When developing these types of systems, a mutual agreement is required between the process engineer or technologist and the knowledge engineer designing the phenomenon model. Often, based on analyses using IT tools, the process engineer finds out new, so far overlooked dependencies, which are of key importance.

\subsection{Description of selected forging tool and hot die forging process}

For the research, the forging tool used in the hot forging process of a lid-type (cover) forging was selected (Fig. 3a). This process is realized on a crank press P-1800T (number of strokes per min: 70), with the nominal force $18 \mathrm{MN}$, in three forging operations; upsetting, roughing and finishing forging (Fig. 3b). The elements (lid-type forging) were forged from steel C45, from cylindrical billets with the dimensions: $D=$ $55 \mathrm{~cm}, L=95 \mathrm{~mm}$ and mass $M=1.77 \mathrm{~kg}$. The input material is heated up to $1150{ }^{\circ} \mathrm{C}$ in an induction furnace. The tools are preheated to the temperature of around $220^{\circ} \mathrm{C}$. The forging, after the forging process, as well as normalizing and machining, is a component of the gearbox in truck cars, as a type of seal at the exit of the drive shaft of the gearbox.

All the tools in this process are made of WCL steel (1.2343). After the heat treatment, they are subjected to nitriding or different surface engineering processes, after which the hardness of the surface layer is at the level of: about $1100 \mathrm{HV}$ (after nitriding) and over $3000 \mathrm{HV}$ (after nitriding + PVD coating. The research concentrated on the tools assigned for the second operation (preliminary forging), which exhibited the lowest hardness, and a detailed analysis was performed on the punch of the upper die (Fig. 4).

This manuscript presents a sensitivity analysis of the artificial neural networks for the developed decision support system, for the analysed forging tool (punch) shown in Fig. 4, after different surface engineering methods have been applied.

\subsection{The main aim of the study}

The mathematical model in the form of a neural network is called the "black box" model. There are, however, several methods that allow us to assess the impact of the selected input
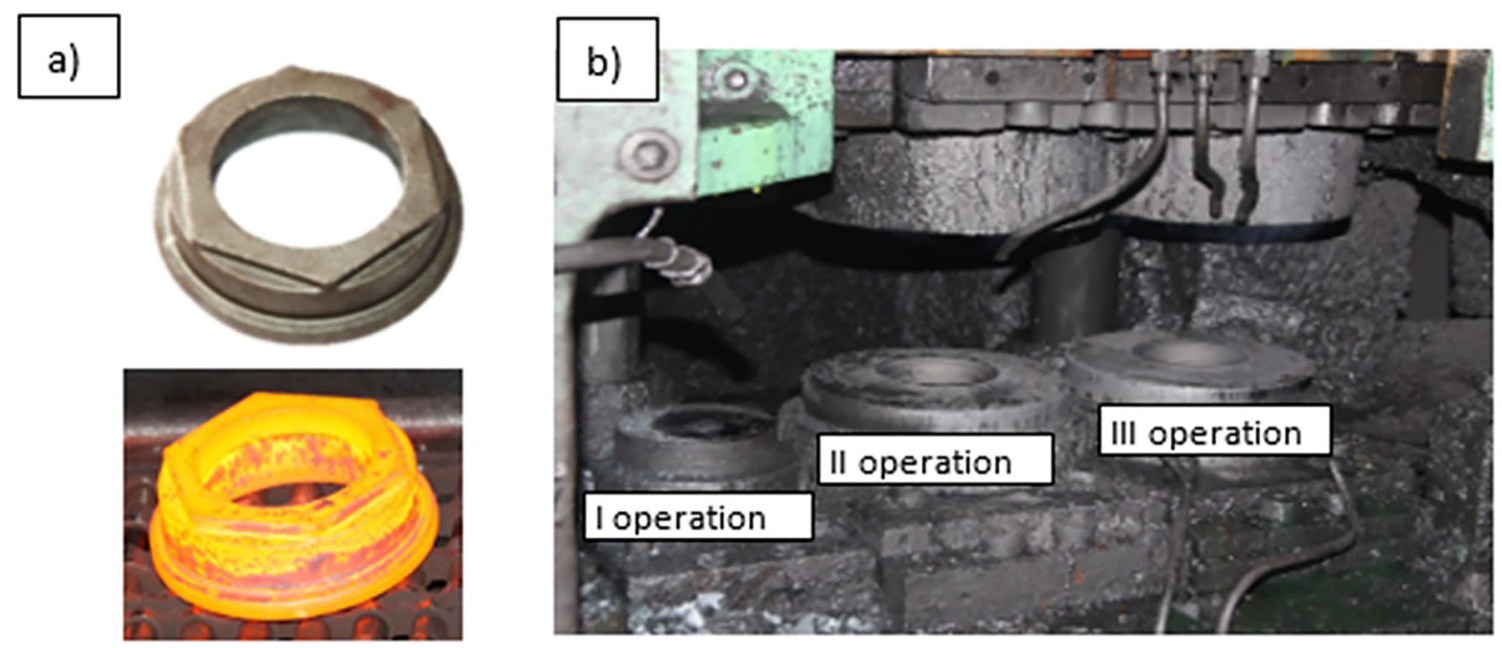

Fig. 3 A view of a a ready element (upper image); a hot forging directly after forging, piercing and trimming (lower image), and $\mathbf{b}$ the press station with successive forging operations 


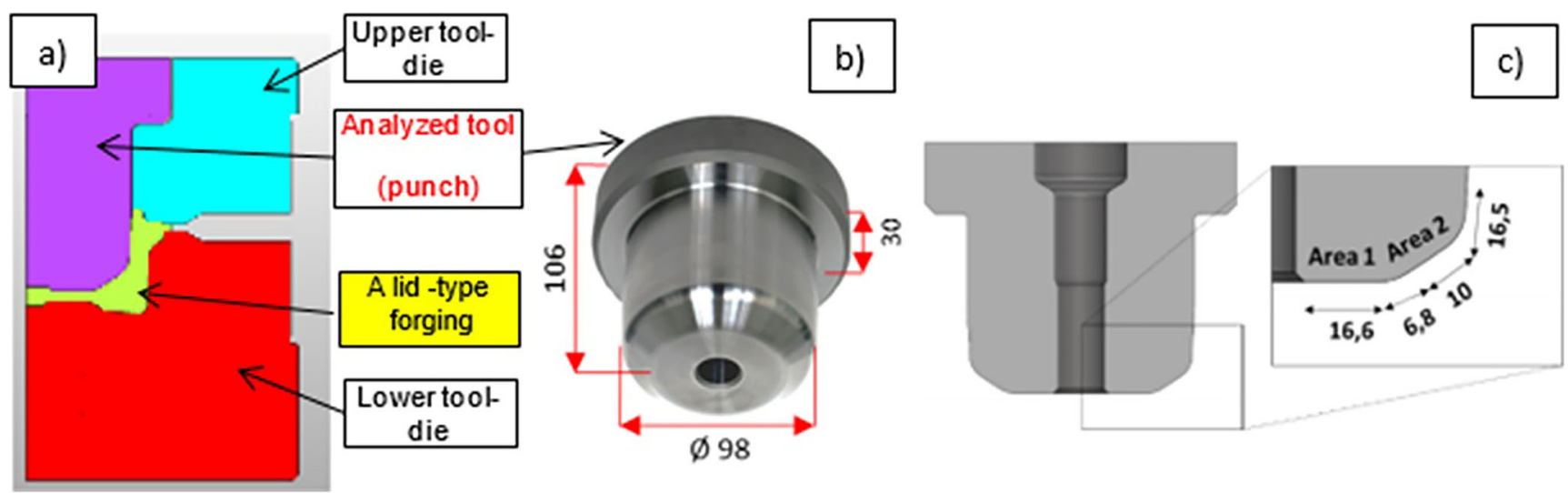

Fig. 4 Analysed process of forging of a lid (cover): a schematic view of the tools in the 2nd forging operation, $\mathbf{b}$ analysed tool—punch, $\mathbf{c}$ detailed dimensions with characteristic areas (distance in $\mathrm{mm}$ ): area 1 (different destructive mechanisms) and area 2 (assumed only abrasive wear)

variables included in the neural network model on the output variable. One of these methods is the sensitivity analysis.

It happens very often that input variables are not independent, so deleting one variable does not always have to cause a loss of model quality, because information about this variable is stored in the values of another variable. Therefore, to check the significance of the input parameters of the developed networks adopted for the analysis (number of forgings, pressure, tool temperature, friction path, type of protective surface layer), a decision was made to carry out these studies.

The most common measure of the network quality is mean squared error (MSE), and it is minimized during the network training process. The measure of the network sensitivity is the so-called quotient of error increase - it indicates how many times the network error will increase after a given variable is removed in relation to the network error with all the analysed variables.

The sensitivity analysis of the developed nine neural networks gives the opportunity to assess the input variables in terms of the importance of their impact on the output variable and also makes it possible to indicate those variables that can be omitted without a loss of network quality as well as the key variables, which are not worth ignoring.

This work proves that all the input variables selected for the analysis are significant. Additionally, they have been ranked in terms of their significance and this can be very useful for technologists and process engineers using the developed system.

\subsection{Neural networks determining the geometric loss of material}

Five neural networks determine the geometric loss of material for tools operating with protective layers, such as a nitrided layer, a pad welded layer and hybrid layers, i.e. AlCrTiSiN, $\mathrm{Cr} / \mathrm{CrN}$ and $\mathrm{Cr} / \mathrm{AlCrTiN}$. The comparison and basic characteristics of these networks are presented in Table 1 . In the training process, each network adopted the training cases typical of the tool operating with a given protective layer. Column 2 (Table 1) presents the number of training cases for each of the developed networks. In the developed networks, the variable metric method, which includes the Broyden-Fletcher-Goldfarb-Shanno (BFGS) method, was adopted as a training algorithm. For each network presented in Table 1, the number of epochs in which the training process was completed was given next to the name of the training algorithm (column 4). The next columns (columns 5 and 6) specify the types of functions that were used to activate the neurons in the hidden layer and in the output layer of the network - tangensoidal, linear, logistic and exponential functions were used here.

In columns 7-9 of Table 1, the results of the linear correlation coefficient calculations are presented for each of the sets (training, test and validation sets). Additionally, the last column (column 10) presents correlation charts for the validation set. The Pearson's linear correlation coefficient $\left(R^{2}\right)$ was determined from Formula (1).

$R^{2}=\frac{\sum_{i=1}^{n}\left(\widehat{y}_{i}-\bar{y}\right)^{2}}{\sum_{i=1}^{n}\left(y_{i}-\bar{y}\right)^{2}}$

where $y_{i}$ is the actually observed value, $\widehat{y}_{i}$ is the theoretical value of output variable determined on the basis of the model and $\bar{y}$ is the arithmetic mean of empirical values of the output variable.

Diagrams of the adopted neural networks to determine the geometric loss of material (wear) for tools operating with protective layers are shown in Fig. 5.

\subsection{Neural networks determining the intensity of the occurrence of typical destructive mechanisms}

Four neural networks determine the intensity of the occurrence of typical destructive mechanisms, i.e. thermal and mechanical fatigue, mechanical wear, abrasive wear and plastic 
Table 1 A set of neural networks calculating the value of wear

\begin{tabular}{|c|c|c|c|c|c|c|c|c|c|}
\hline \multicolumn{6}{|c|}{ Basic characteristics of developed networks } & \multicolumn{4}{|c|}{ Network quality assessment parameter $R^{2}$} \\
\hline 1 & 2 & 3 & 4 & 5 & 6 & 7 & 8 & 9 & 10 \\
\hline $\begin{array}{l}\text { Network } \\
\text { identifier }\end{array}$ & $\begin{array}{c}\text { Number of } \\
\text { cases }\end{array}$ & \begin{tabular}{|c|} 
Network \\
architecture
\end{tabular} & $\begin{array}{c}\text { Training } \\
\text { algorithm }\end{array}$ & $\begin{array}{c}\text { Activation } \\
\text { (Hidden) }\end{array}$ & $\begin{array}{c}\text { Activation } \\
\text { (Output) }\end{array}$ & $\begin{array}{c}\text { Training } \\
\text { set }\end{array}$ & $\begin{array}{c}\text { Test } \\
\text { set }\end{array}$ & $\begin{array}{c}\text { Validation } \\
\text { set }\end{array}$ & $\begin{array}{c}\text { Correlation charts for } \\
\text { validation set }\end{array}$ \\
\hline $\begin{array}{c}\text { ANN-1-1 } \\
\text { Nitrided layer } \\
(\mathrm{GN})\end{array}$ & 156 & MLP 4-5-1 & BFGS 170 & Exponential & Exponential & 0.957 & 0.951 & 0.874 & \\
\hline $\begin{array}{c}\text { ANN-1-2 } \\
\text { Pad welded layer }\end{array}$ & 98 & MLP 4-6-1 & BFGS 41 & Exponential & Exponential & 0.967 & 0.890 & 0.956 & \\
\hline $\begin{array}{c}\text { ANN-1-3 } \\
\text { Hybrid layer } \\
\text { GN/CrN }\end{array}$ & 279 & MLP 4-5-1 & BFGS 78 & Tanh & Linear & 0.900 & 0.964 & 0.923 & 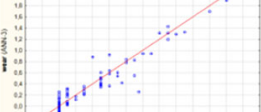 \\
\hline $\begin{array}{c}\text { ANN-1-4 } \\
\text { Hybrid layer } \\
\text { GN/AlCrTiN }\end{array}$ & 193 & MLP 4-10-1 & BFGS 126 & Exponential & Linear & 0.918 & 0.956 & 0.882 & 4 \\
\hline $\begin{array}{c}\text { ANN-1-5 } \\
\text { Hybrid layer } \\
\text { GN/AlCrTiSiN }\end{array}$ & 168 & MLP 4-10-1 & BFGS 74 & Tanh & Logistic & 0.957 & 0.987 & 0.952 & \\
\hline
\end{tabular}

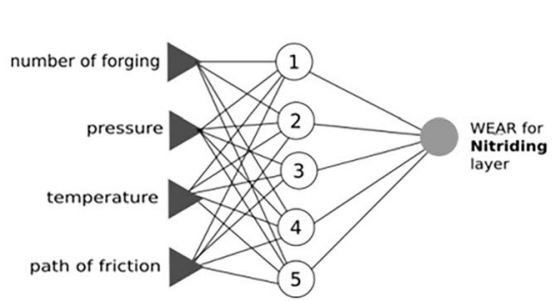

a)

\section{d)}

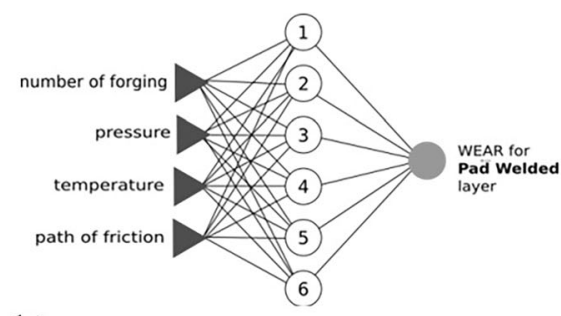

b)

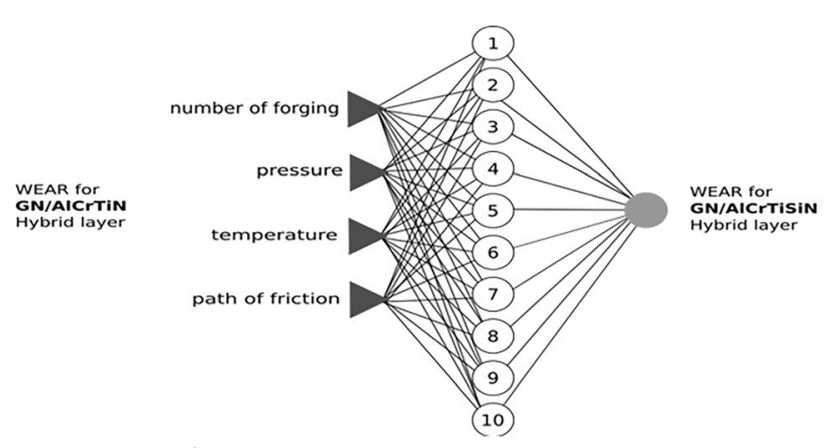

e)

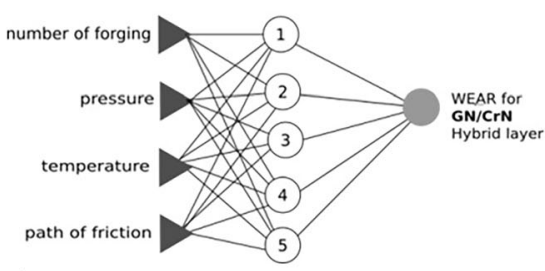

c) 


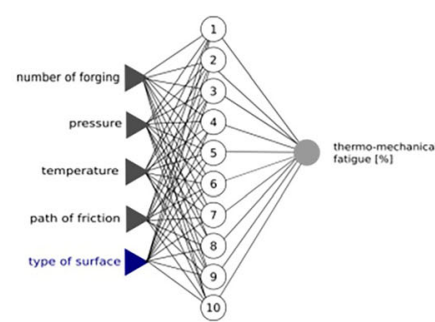

a)

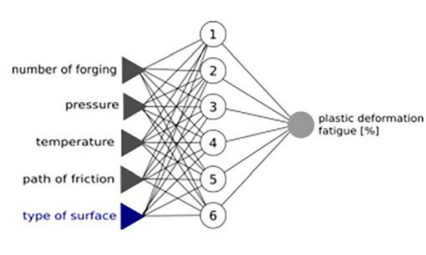

c)

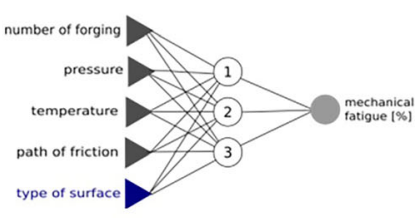

d)

Fig. 6 Diagrams of neural networks calculating the intensity of the occurrence of destructive mechanisms: a thermo-mechanical fatigue, $\mathbf{b}$ abrasive wear, c plastic deformation and $\mathbf{d}$ mechanical fatigue

deformation. Diagrams of the neural networks calculating the intensity of the occurrence of destructive mechanisms are shown in Fig. 6. Basic characteristics of these networks are presented in Table 2 .

It should be noted that the "layer type" variable is treated here as one of the input variables, so these networks are characterized by five neurons in the input layer. In developing the source data used to design these networks, it has been assumed that each mechanism is represented by a number within the range from 0 to 1 . Value 0 means that the given mechanism of destruction does not occur in a given case. Value 1 means that there is only one mechanism of destruction. In each case, the sum of the values assigned to all four destruction mechanisms can be 1 . Thus, each of the developed networks, i.e. ANN-2, ANN-3, ANN-4 and ANN-5, determines an approximate percentage contribution of each mechanism to the tool destruction.

The studies of the system creation process and the results generated therefrom are described in detail in ref. [24, 25]. The research described in this work is devoted to the sensitivity analysis of neural networks implemented in the system. Based on the developed networks, in addition to predicting the values of individual explained (output) variables, it is possible to estimate which input variables have the greatest impact on the result.

\subsection{Sensitivity analysis}

The adopted method of sensitivity analysis of the input variables is implemented after the network training process is completed and the network error is determined (Error) Formula (2).

Error $=\frac{1}{n} \sum_{i=1}^{n}\left(y_{i}-\widehat{y_{i}}\right)^{2}$

where $y_{i}$ is the actually observed value and $\widehat{y}_{i}$ is the theoretical value of output variable determined on the basis of the model.

The level of significance of input variables can be assessed by way of eliminating them from the network input, re-implementing the training process and determining a new network error $\left(\right.$ Error $\left._{i}\right)$. If a certain amount of data is rejected, an increase in the network error should be expected. Therefore, the basic measure of network sensitivity is the quotient $W$ of the error obtained at the network startup for a data set without one variable Error $_{i}$ and the error obtained for a dataset with all the variables Error (3).

$W=\frac{\text { Error }_{i}}{\text { Error }}$

The analysis shows what loss is incurred when a specific variable is rejected (Fig. 7). The greater the network error after the

Table 2 A set of neural networks calculating the intensity of the occurrence of destructive mechanisms

\begin{tabular}{|c|c|c|c|c|c|c|c|}
\hline \multicolumn{5}{|c|}{ Basic characteristics of developed networks } & \multicolumn{3}{|c|}{$\begin{array}{l}\text { Network quality assessment } \\
\text { parameter } R^{2}\end{array}$} \\
\hline Network identifier & $\begin{array}{l}\text { Network } \\
\text { architecture }\end{array}$ & $\begin{array}{l}\text { Training } \\
\text { algorithm }\end{array}$ & $\begin{array}{l}\text { Activation } \\
\text { (hidden) }\end{array}$ & $\begin{array}{l}\text { Activation } \\
\text { (output) }\end{array}$ & $\begin{array}{l}\text { Training } \\
\text { set }\end{array}$ & $\begin{array}{l}\text { Test } \\
\text { set }\end{array}$ & $\begin{array}{l}\text { Validation } \\
\text { set }\end{array}$ \\
\hline ANN-2 thermo-mechanical fatigue & MLP 5-11-1 & BFGS 428 & Tanh & Linear & 0.916 & 0.871 & 0.871 \\
\hline ANN-3 abrasive wear & MLP 5-6-1 & BFGS 182 & Tanh & Exponential & 0.889 & 0.874 & 0.874 \\
\hline ANN-4 plastic deformation & MLP 5-6-1 & BFGS 115 & Tanh & Tanh & 0.824 & 0.896 & 0.776 \\
\hline ANN-5 mechanical fatigue & MLP 5-3-1 & BFGS 11 & Exponential & Logistic & 0.788 & 0.699 & 0.700 \\
\hline
\end{tabular}


a)

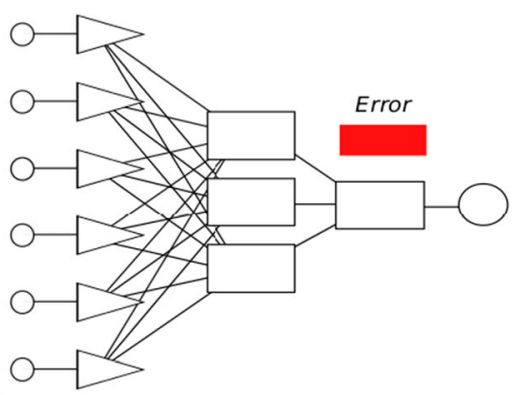

Fig. 7 Scheme of analysis of the significance of input variab
unsignificant, c) removing from the network significant [27]

variable is rejected compared to the original error (for a network with all the input variables), the more sensitive the network to the lack of this variable. If the error quotient is 1 or less, then deleting the variable does not affect the network quality and even improves it. After conducting a sensitivity analysis for all the analysed variables, they can be ranked in order of importance [27].

\section{The results of sensitivity analysis}

\subsection{Sensitivity analysis of neural networks determining the geometric loss}

The results of the sensitivity analysis of neural networks determining the geometric loss of tools operating with different surface layers are presented in Table 3. For each of the variables, the coefficient $W$ was calculated as the quotient of the network error obtained at the network startup for a data set without one variable and the error obtained for a data set with all the variables. The results are summarized in Table 3 and illustrated in Fig. 8.

In the case of the geometric loss determined by the ANN-11 network for the nitrided layer and the ANN-1-2 network for the pad welded layer, the tool temperature has the greatest impact on the results, which means that tools with a nitrided layer and a pad welded layer are the most sensitive to changes under thermal conditions. This confirms the observations made in industrial practice showing that these surface treatment variants applied to forging tools do not provide a resistance to temperature but rather to abrasive wear. In the case of the ANN-1-3 network for the GN/CrN hybrid layer and the ANN-1-4 network for the GN/AlCrTiN hybrid layer, the friction path has the greatest impact on the obtained results. As in the previous variants, these networks are more sensitive to the forged material movement along the tool. It should also be noted that the second factor affecting the network sensitivity is temperature. Therefore, in industrial forging processes, tools with applied hybrid layers, in particular with hybrid layers containing chromium, are resistant to temperature changes, but less resistant to abrasive wear.

The results obtained for the ANN-1-5 network (GN/ $\mathrm{AlCrTiSiN}$ ) are very interesting because they indicate that the use of the GN/AlCrTiSiN hybrid layer on forging tools makes them sensitive to temperature, unlike tools coated with the GN/CrN and GN/AlCrTiN hybrid layers. Moreover, the second factor affecting sensitivity is pressure and not the path of friction, which, in the ranking of sensitivity factors, is placed after pressure. Probably, in the case of the ANN-1-5

Table 3 The results of the sensitivity analysis of neural networks determining the geometric loss

\begin{tabular}{|c|c|c|c|c|c|c|c|c|c|}
\hline \multicolumn{2}{|c|}{$\begin{array}{c}\text { ANN-1-1 } \\
\text { Nitrided layer (GN) }\end{array}$} & \multicolumn{2}{|c|}{$\begin{array}{c}\text { ANN-1-2 } \\
\text { Pad welded layer }\end{array}$} & \multicolumn{2}{|c|}{$\begin{array}{c}\text { ANN-1-3 } \\
\text { Hybrid layer } \\
\text { GN/CrN }\end{array}$} & \multicolumn{2}{|c|}{$\begin{array}{c}\text { ANN-1-4 } \\
\text { Hybrid layer: } \\
\text { GN/AlCrTiN }\end{array}$} & \multicolumn{2}{|c|}{$\begin{array}{c}\text { ANN-1-5 } \\
\text { Hybrid layer } \\
\text { GN/AlCrTiSiN }\end{array}$} \\
\hline variable & $\bar{W}$ & variable & $\mathbf{W}$ & variable & $\mathbf{W}$ & variable & $\mathbf{W}$ & variable & $\mathbf{W}$ \\
\hline Temperature & 67.29 & Temperature & 120.00 & Friction path & 21.353 & Friction path & 20.305 & Temperature & 36.126 \\
\hline Friction path & 41.05 & Pressure & 86.41 & Temperature & 18.025 & Temperature & 19.394 & Pressure & 13.111 \\
\hline Pressure & 6.70 & $\begin{array}{l}\text { Number of } \\
\text { forgings }\end{array}$ & 26.42 & $\begin{array}{l}\text { Number of } \\
\text { forgings }\end{array}$ & 10.574 & Pressure & 17.023 & Friction path & 12.409 \\
\hline $\begin{array}{l}\text { Number of } \\
\text { forgings }\end{array}$ & 6.04 & Friction path & 22.64 & Pressure & 10.037 & $\begin{array}{l}\text { Number of } \\
\text { forgings }\end{array}$ & 9.667 & $\begin{array}{l}\text { Number of } \\
\text { forgings }\end{array}$ & 5.157 \\
\hline
\end{tabular}




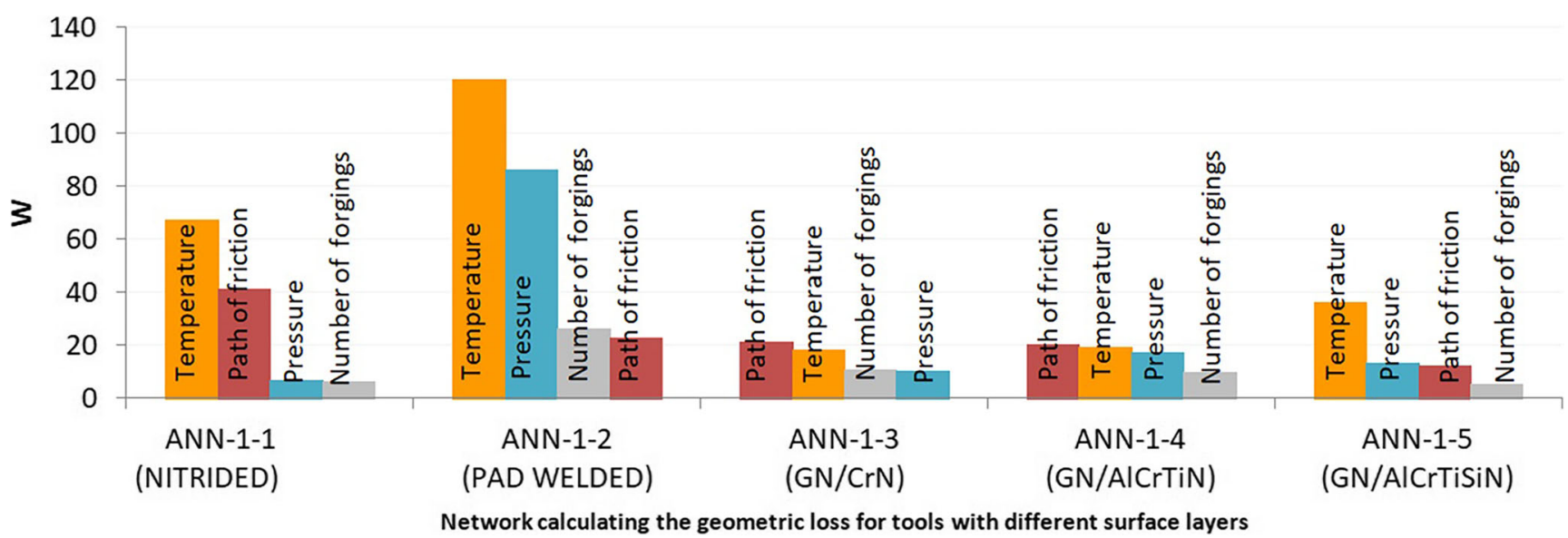

Fig. 8 Presentation of the results of the sensitivity analysis of neural networks calculating the geometric loss for tools operating with different surface layers

network, the addition of Si to the hybrid layer makes this layer slightly harder compared to the previous two types of layers, which is further confirmed by the results of hardness tests. This, in turn, confirms that this type of thermo-chemical treatment, by making the tools more sensitive to temperature, provides a protection against thermal and thermo-mechanical fatigue which is slightly inferior to the layers examined in the ANN-1-3 and ANN-1-4 networks, while making them more resistant to abrasive wear.

\subsection{Sensitivity analysis of neural networks determining the intensity of the occurrence of destructive mechanisms}

The results of the sensitivity analysis of neural networks (ANN-2, ANN-3, ANN-4, ANN-5) determining the intensity of the occurrence of destructive mechanisms such as thermomechanical fatigue, abrasive wear, plastic deformation and mechanical fatigue are presented in Table 4. Based on the calculated coefficient $W$, the input variables occurring in these networks have been ranked according to their significance for each network.

In the case of the ANN-2 neural network, which determines the intensity of the occurrence of the mechanism of thermomechanical fatigue, it can be seen that the most significant variables are temperature and pressure, i.e. precisely those physical quantities that, also during industrial forging processes, most effectively encourage the occurrence of this mechanism. The results obtained for the ANN-3 network, which determines the intensity of the occurrence of abrasive wear, indicate that the greatest significance is exhibited by the path of friction, followed by temperature and pressure. However, translating these results into the forging process, it seems that, compared to temperature, pressure is slightly more responsible for the intensity of this mechanism. In the case of forging tools, high pressure at large friction distances increases the abrasive wear, while high temperature is more conducive to the local tempering of tool material, as a consequence of which there is an increase in plastic deformation. As regards the results of the sensitivity analysis performed for the networks determining the occurrence of plastic deformation

Table 4 The results of the sensitivity analysis of neural networks determining the intensity of the occurrence of destructive mechanisms

\begin{tabular}{|c|c|c|c|c|c|c|c|}
\hline \multicolumn{2}{|c|}{$\begin{array}{c}\text { ANN-2 } \\
\text { thermo-mechanical fatigue }\end{array}$} & \multicolumn{2}{c|}{$\begin{array}{c}\text { ANN-2 } \\
\text { abrasive wear }\end{array}$} & \multicolumn{2}{c|}{ ANN-4 } \\
plastic deformation & \multicolumn{3}{c|}{$\begin{array}{c}\text { ANN-5 } \\
\text { mechanical fatigue }\end{array}$} \\
\hline Variable & W & variable & W & variable & W & variable & W \\
\hline Temperature & 8,4098 & Friction path & 9,2158 & Temperature & 1,0020 & Pressure & 1,0127 \\
\hline Pressure & 6,6410 & Temperature & 7,2546 & Friction path & 1,0015 & $\begin{array}{c}\text { Number of } \\
\text { forgings }\end{array}$ & 1,0079 \\
\hline $\begin{array}{c}\text { Number of } \\
\text { forgings }\end{array}$ & 4,4217 & Pressure & 6,2056 & Pressure & 1,0002 & Friction path & 1,0016 \\
\hline $\begin{array}{c}\text { Friction path } \\
\text { finger }\end{array}$ & 1,9293 & $\begin{array}{c}\text { Number of } \\
\text { forgings }\end{array}$ & 2,0225 & $\begin{array}{c}\text { Number of } \\
\text { forgings }\end{array}$ & 1,0000 & Temperature & 1,0010 \\
\hline Layer & 1,2053 & Layer & 1,1743 & Layer & 0,9998 & Layer & 1,0007 \\
\hline
\end{tabular}


(ANN-4) and mechanical fatigue (ANN-5), the order in which individual factors exert their influence is somewhat puzzling, because, as it has already been mentioned, the greatest impact on plastic deformation in the industrial process is demonstrated by high temperature, followed by pressure and path of friction. In forging processes, the occurrence of mechanical fatigue is mainly caused by high pressure, and, to a lesser extent, by the number of forgings, because, in the case of sharp edges or right angles in the tool, microcracks may initially appear as a result of stress concentration. Over time, i.e. with the increase in the number of produced forgings, propagation and further development of cracks occurs, leading to complete tool breakage. When the results obtained for the last two networks (ANN-4 and ANN-5) are analysed, it can be seen that they are incompatible with the tool behaviour observed during its operation in industrial forging processes. However, looking at the values of the coefficient $W$, one can see that they are similar and almost at the same level. Therefore, for these cases, it is difficult to speak about differences in the level of significance. The results show, which is also in agreement with the quality parameters of these two networks (Table 2), that they are characterized by the least favourable matching parameters and thus by the largest predictive error. Additionally, as the analysis of the source data showed, in the training process, these networks had the least numerous training sets. Therefore, the training process should be carried out again on a new complete training set.

\subsection{Summary}

The paper presents the results of a sensitivity analysis and assessment of the developed nine sets of neural networks in terms of the significance of selected key process parameters and their impact on the size of the geometric loss of tool material and the occurrence of major destructive mechanisms. The sensitivity analysis was carried out to identify the most important input parameters, which made it possible to rank them in the order from the most significant to the least significant for the results obtained.

Based on the experience of expert technologists in industrial forging processes, a verification of the obtained results was performed. It was found that, in the case of the first five networks regarding the geometric loss of the forging tool (ANN-1-1 to ANN-1-5), the obtained results were consistent with reality and confirmed the observations and analyses of experts in industrial processes. The situation was similar in the case of the next two networks regarding the intensity of the occurrence of the main destructive mechanisms (ANN-2 and ANN-3). In the case of the last two networks (ANN-4 and ANN-5) regarding the intensity of the occurrence of plastic deformation and mechanical fatigue, the obtained results deviated from reality, although, as the research has shown, the values of the sensitivity indicators determined for individual process parameters were almost at the same level, which can be explained by the small training data sets used in these networks.

The results of the sensitivity analysis obtained in this work can be very useful for technologists and process engineers, whose task is to optimize the operating parameters of the process to make the forging tool life as long as possible. Moreover, based on the obtained results, it can be concluded that the developed sets of neural networks were designed correctly. It should be emphasized and remembered that the correctness of the obtained results must be verified and confirmed under industrial conditions. Therefore, continuous cooperation, exchange of knowledge and experience, and information flow between knowledge engineers, IT specialists and process technologists or engineers are necessary.

The results of the research and analysis can be very helpful in the construction of various IT tools, such as the useful decision support systems, which can successfully support engineers and technologists working in $\mathrm{R} \& \mathrm{D}$ departments of companies and industrial plants involved in the production of die forgings.

Acknowledgments The work was realized as a part of fundamental research financed by the Ministry of Science and Higher Education, grant no. 16.16.110.663.

Open Access This article is licensed under a Creative Commons Attribution 4.0 International License, which permits use, sharing, adaptation, distribution and reproduction in any medium or format, as long as you give appropriate credit to the original author(s) and the source, provide a link to the Creative Commons licence, and indicate if changes were made. The images or other third party material in this article are included in the article's Creative Commons licence, unless indicated otherwise in a credit line to the material. If material is not included in the article's Creative Commons licence and your intended use is not permitted by statutory regulation or exceeds the permitted use, you will need to obtain permission directly from the copyright holder. To view a copy of this licence, visit http://creativecommons.org/licenses/by/4.0/.

\section{References}

1. Hawryluk M (2016) Methods of analysis and increasing the durability of forging tools used in hot die forging processes. Scientific Publisher of the Institute for Sustainable Technologies, Radom

2. Kima DH, Leeb HC, Kimc BM, Kimd KH (2012) Estimation of die service life against plastic deformation and wear during hot forging processes. J Mater Process Technol 212:1742-1752

3. Markov O, Zlygoriev V, Gerasimenko O, Hrudkina N, Shevtsov S (2018) Improving the quality of forgings based on upsetting the workpieces with concave facets. East Eur J Enterp Technol 5/1(95):16-24. https://doi.org/10.15587/1729-4061.2018.142674

4. Markov O, Diachenko Y, Aliieva L, Zharikov S, Hrudkina N, Bondarenko V, Pohorielov M (2019) Determination of the peculiarities of obtaining coatings of different hardness on structural steel at diffusion metallization. East Eur J Enterp Technol 6/12(102):14-21. https://doi.org/10.15587/1729-4061.2019. 188936 
5. Choi C, Groseclose A, Altan T (2012) Estimation of plastic deformation and abrasive wear in warm forging dies. J Mater Process Technol 212(8): 1742-1752

6. Persson A, Hogmark S, Bergstroma J (2005) Thermal fatigue cracking of surface engineered hot work tool steels. Surf Coat Technol 191:216-227

7. Berti GA, Monti M (2005) Thermo-mechanical fatigue life assessment of hot forging die steel. Fatigue Fract Eng Mater Struct 28(11):1025-1034

8. Smirnov LR, S. Shveykin V. (2000) Damage mechanics for the fracture prediction of metal forming tools. Int J Fract 103(2):111126

9. Hawryluk M, Zwierzchowski M (2017) Phenomena and degradation mechanisms in the surface layer of die inserts used in the hot forging processes. Eng Fail Anal 79:313-329

10. Hawryluk M (2016) Review of selected methods of increasing the life of forging tools in hot die forging processes. Arch Civil Mech Eng 16(4):845-866

11. Paschke H, Yilkiran T, Lippold L et al (2015) Adapted surface properties of hot forging tools using plasma technology for an effective wear reduction. Wear 330:429

12. Myung JS, Sung SK, Eung-Ahn L, Kim KH (2002) Properties of TiBN coating on the tool steels by PECVD and its applications. J Mater Process Technol 130:266-271

13. Prabakaran M, Kumar S, Ramyesh KR, Srinivasan RV (2014) Characterization and optimization of $\mathrm{CrN}$ coatings on tool steels (6959). Int J Mech Ind Technol 2:108-112

14. Podgrajšek M, Glodežb S, Ren Z (2015) Failure analysis of forging die insert protected with diffusion layer and PVD coating. Surf Coat Technol 276:521-528

15. Klimek KS, Ahn H, Seebach I, Wang M, Rie KT (2003) Duplex process applied for diecasting and forging tools. Surf Coat Technol 174-175:677-680

16. Dobrzański LA, Polok M, Adamiak M (2004) Improvement of wear resistance of hot work steels by PVD coatings deposition. J Mater Process Technol 155:1995-2001

17. Gronostajski Z, Hawryluk M, Jakubik J, Kaszuba M, Misiun G, Sadowski P (2015) Solution examples of selected issues related to die forging. Arch Metall Mater 60(4):2773-2781

18. Lu B, Ou H, Long H (2011) Die shape optimisation for net-shape accuracy in metal forming using direct search and localised response surface methods. Struct Multidiscip Optim 44:529-545

19. Joshy S., Jayadevan KR., Ramesh A., et al. Microstructural evolution and microhardness response of H11 hot forging dies. World Journal of Engineering 2019; 16(5): 573-581

20. https://www.totalmateria.com/page $\cdot \operatorname{aspx} ? \mathrm{ID}=\mathrm{CheckArticle} \&$ site $=$ kts\&NM=234

21. Montanari R, Varone A (2019) Processing-structure-property relationships in metals, 2019. MDPI@Books. https://doi.org/10.3390/ books978-3-03921-771-7

22. Sun Y, Zeng WD, Zhao YQ, Shao YT, Zhou YG (2012) Modeling the correlation of composition-processing-property for TC11 titanium alloy based on principal component analysis and artificial neural network. J Mater Eng Perform 21(11):2231-2237
23. Hashemzadeh H, Eftekhari SA, Loh-Mousavi M (2017) Forging pre-form dies optimization using artificial neural networks and continuous genetic algorithm. Biosci Biotechnol Res Commun 10((1) Special Issue: SI):74-86

24. Mrzygłód B, Hawryluk M, Gronostajski Z, Opaliński A, Kaszuba M, Polak S, Widomski P, Ziemba J, Zwierzchowski M (2018) Durability analysis of forging tools after different variants of surface treatment using a decision-support system based on artificial neural networks. Arch Civil Mech Eng Pol Acad Sci; ISSN 1644-9665 18(4):1079-1091

25. Hawryluk M, Mrzygłód B (2018) A system of analysis and prediction of the loss of forging tool material applying artificial neural networks. J Min Metall Sect B Metall 54(3):323-333

26. Hawryluk M, Mrzyglod B (2017) A durability analysis of forging tools for different operating conditions with application of a decision support system based on artificial neural networks (ANN). Eksploatacja i Niezawodnosc-Maint Reliabil 19(3):338-348

27. Tadeusiewicz R, Szaleniec M (2015) Lexicon of neural networks, Publisher of the 'Projekt Nauka' Foundation, Wrocław

28. Li M, Liu,X, Xiong A. Prediction of the mechanical properties of forged TC11 titanium alloy by ANN. J Mater Process Technol 2012; 121(1): 1-4

29. Sun Y, Hu L (2014) Modelling optimisation of hot processing parameters of Ti-6Al-4V alloy using artificial neural network and genetic algorithm. Mater Res Innov 18:1052-1056

30. Katayama T, Akamatsu M, Tanaka Y (2004) Construction of PC based expert system for cold forging process design. J Mater Process Technol 155-156:1583-1589

31. Subba Rao AV, Pratihar DK (2007) Fuzzy logic-based expert system to predict the results of finite element analysis. Knowl Based Syst 20:37-50

32. Azari A, Poursina M, Poursina D (2014) Radial forging force prediction through MR, ANN and ANFIS models. Neural Comput Applic 25(3-4):849-858

33. Gangopadhyay T, Kumar D, Pratihar I (2014) Expert system to predict forging load and axial stress. Appl Soft Comput 11(1): 744-753

34. Gronostajski Z, Hawryluk M, Kaszuba M, Marciniak M, Niechajowicz A, Polak S, Zwierzchwoski M, Adrian A, Mrzygłód B, Durak J (2016) The expert system supporting the assessment of the durability of forging tools. Int J Adv Manuf Technol 82(9-12):1973-1991

35. Hawryluk M, Mrzygłód B (2016) Application of adaptive neurofuzzy inference system (ANFIS) to predict the wear of forging tools, metal 2016: 25 International Conference on Metallurgy and Materials: May 2016, Brno, Czech Republic, Eu: list of abstracts. — Ostrava : TANGER Ltd., cop. 2016. — ISBN: 978-80-8729466-6. - S. 90

Publisher's note Springer Nature remains neutral with regard to jurisdictional claims in published maps and institutional affiliations. 